Fajar Historia: Jurnal Ilmu Sejarah dan Pendidikan

Volume 2 nomor 2, Desember 2018, Hal. 25 - 34

\title{
PENGARUH METODE BERTIMBAL BALIK (RECIPROCAL TEACHING) TERHADAP BERPIKIR KRITIS SISWA PADA MATA PELAJARAN SEJARAH \\ KELAS XI IPS SMA NEGERI 2 AIKMEL TAHUN PELAJARAN 2018/2019
}

\author{
${ }^{1}$ Celine Nurfitri, ${ }^{2}$ Badarudin, ${ }^{3} B$. Fitri Rahmawati \\ 1, 2,3 Universitas Hamzanwadi \\ celin@gmail.com, fitri.fkiphamzanwadi@gmail.com
}

\begin{abstract}
Abstrac
The preliminary study shows that History is an unattractive, boring, difficult subject, etc. that shows students actually don't like the lesson. This situation can be aggravated if the teacher who teaches it is monotonous, too theoretical, and abstract, lack of textbooks, plus an ever-changing curriculum. Students' critical thinking skills can be very diverse, especially can be seen from the lack of active participation of students in learning, the low response and courage of students to express opinions. Facing this reality, researchers want to try reciprocal teaching method that is assumed to have a positive effect on students' critical thinking skills. The purpose of this study was to determine the effect of Reciprocal teaching models on students' critical thinking skills in History subjects in the XI IPS class in SMAN 2 academic year 2017/2018. This type of research is experimental research. The experimental group was given treatment using the Reciprocal Teaching method while the control group using conventional methods. Data on the results were collected through observation sheet. data analysis was performed with t-test formula. Based on the results of data analysis obtained $t$-count $=6.370$ and $t$-table 2.00 with $d k 58$ and a significance level of 5\% so that the null hypothesis is rejected and the alternative hypothesis is accepted, which means there is a positive and significant influence using the reciprocal method (Reciprocal Teaching ) on students' critical thinking skills in History subjects in class XI IPS students of SMAN 2 Aikmel academic year 2018/2019.
\end{abstract}

Key Word: Reciprocal Teaching), Critical Thingking.

\section{PENDAHULUAN}

Pendidikan merupakan komponen yang sangat penting dalam mencetak sumber daya manusia yang berkualitas. Pendidikan sangat membantu peserta didik dalam usaha mengembangkan dan menitikberatkan pada perkembangan pengetahuan, kecakapan dan nilai sikap serta pola tingkah laku yang berguna bagi hidupnya. Di dalam pendidikan terdapat suatu kegiatan belajar dimana dalam kegiatan belajar tersebut beberapa hal pokok yang terjadi, yaitu bahwa pada belajar akan membawa perubahan-perubahan, dan 
Pengaruh Metode Bertimbal Balik.....Celine dkk

perubahan tersebut terjadi akan adanya usaha dan kecakapan untuk meraih perubahan tersebut. Belajar senantiasa merupkan tingkah laku atau penampilan, dengan serangkaian kegiatan misalnya dengan membaca, mengamati, mendengarkan, dan meniru. Belajar juga mempunyai peran penting dalam mempertahankan kehidupan di tengah-tengah persaingan yang semakin ketat.

Sekolah menengah atas (SMA/MA) merupakan bentuk satuan pendidikan sebagaimana di tegskan dalam Undang-undang Sistem Pendidikan Nasional, merupakan pendidikan menengah yang mempersiapkan peserta didik untuk mampu bersaing dalam persaingan gelobal. Peserta didik harus menempuh kegiatan pembelajaran yang cukup baik untuk memperoleh lulusan yang berkualitas. Hasil dari kegiatan belajar tersebut adalah perestasi belajar. Pemerintah mengadakan perbaikan mutu pendidikan di indonesia dengan mengambil kebijakan dalam sistem pendidikan nasional. Salah satu kebijakan pemerintah yaitu dengan pembaharuan kurikulum, sistem belajar, dan sistem evaluasi keberhasilan belajar.

Sejarah merupakan salah satu pelajaran yang di ajarkan kepada siswa di SMA atau MA. Sejarah di ajarkan pada kelas program IPS maupun IPA. Pembelajaran Sejarah di sekolah memiliki tujuan agar siswa mampu menumbuhkan rasa nasionalisme dan berpikir kritis. Dalam pembelajaran sejarah tentu tidak terleps dari interaksi guru dan siswa. Pembelajaran sejarah dapat di sampaikan secara objektif agar siswa dapat memahami hikmah dari mempelajari sejarah.

Belajar sejarah adalah belajar mengenai nilai dan makna dari suatu peristiwa yang dengan itu dapat diambil suatu pelajaran. Oleh karena itu, belajar sejarah tidak hanya belajar tentang fakta-fakta kering belaka yang hanya mengembangkan tingkat berpikir yang rendah. Akan tetapi lebih dari itu, untuk dapat menangkap makna dari suatu peristiwa masa lalu, dibutuhkan kemampuan berpikir yang lebih tinggi, salah satunya adalah kemampuan berpikir kritis.

Gunawan (2003: 177-178) menyatakan bahwa keterampilan berpikir kritis adalah kemampuan untuk berpikir pada level yang kompleks dan menggunakan peruses analisis dan evaluasi. Berpikir kritis melibatkan keahlian berpikir induktif seperti mengenai 
Pengaruh Metode Bertimbal Balik.....Celine dkk

hubungan, menganalisis masalah yang bersifat terbuka, menentukan sebab dan akibat, membuat kesimpulan dan memberhitungkan data yang relevan. Menurut Santrock (2011: 359), pemikiran kritis adalah pemikiran reflektif dan produktif, serta melibatkan evaluasi bukti. Jensen (2011: 195) berpendapat bahwa berpikir kritis berarti proses mental yang efektif dan handal, digunakan dalam mengejar pengetahuan yang relevan dan benar tentang dunia. Cece Wijaya (2010: 72) juga mengungkapkan gagasannya mengenai kemampuan berpikir kritis, yaitu kegiatan menganalisis ide atau gagasan ke arah yang lebih spesifik, membedakannya secara tajam, memilih, mengidentifikasi, mengkaji dan mengembangkannya ke arah yang lebih sempurna. Idealnya pembelajaran sejarah adalah wahana bagi setiap peserta didik untuk berpikir jauh lebih kritis, mampu memahami makna atau nilai dari setiap peristiwa yang pernah terjadi, bukan sekedar mengingat tokoh, fakta, dan tahun kejadian. Esensi terpenting, dalam setiap peristiwa sejarah yang pernah terjadi, peserta didik diharapkan mampu untuk mengambil nilai-nilai positif yang patut untuk diteladani (Hermanto, 2016).

Kemampuan berpikir kritis diperlukan untuk menganalisis suatu peristiwa dengan mengevaluasi bukti yang ada. Seperti yang dinyatakan Ennis (1996) bahwa berpikir kritis adalah berpikir secara beralasan dan reflektif dengan menekankan pada pengambilan keputusan tentang apa yang harus dipercayai atau dilakukan. Dengan kata lain, pengambilan keputusan diambil setelah dilakukan refleksi dan evaluasi pada apa yang dipercayai. Sejalan dengan itu Fahrurrozi (2011: 81) mengemukakan bahwa berpikir kritis adalah proses sistematis yang memberikan kesempatan kepada siswa untuk merumuskan dan mengevaluasi keyakinan dan pendapat mereka sendiri. Sementara itu Kusumaningsih (2011: 19) mengemukakan bahwa berpikir kritis merupakan proses berpikir secara tepat, terarah, beralasan, dan reflektif dalam pengambilan keputusan yang dapat dipercaya. Terlebih lagi bahwa topik pembelajaran sejarah masih banyak yang masih kontroversial. Disinilah seharusnya dilakukan pembelajaran yang memberikan kesempatan kepada siswa untuk memberikan penilaian untuk dapat mengambil keputusan. Pembelajaran sejarah dapat di sampaikan secara Objektif agar siswa dapat memahami hikmah dari mempelajari sejarah. 
Pengaruh Metode Bertimbal Balik.....Celine dkk

Untuk mengembangkan kemampuan berpikir kritis siswa pada pembelajaran sejarah, tidaklah cukup hanya dengan mengandalkan pembelajaran konvensional yang selama ini menuai banyak kritikan. Seperti yang dinyatakan Alfian (2011) bahwa sudah bukan rahasia lagi, bahwa Sejarah merupakan mata pelajaran yang tidak menarik, membosankan, sulit dan lain-lain yang menunjukkan sebenarnya siswa tidak menyukai pelajaran itu. Keadaan ini dapat diperparah jika guru yang mengajarkannya monoton, terlalu teoretis, dan abstrak, kurangnya buku ajar, ditambah kurikulum yang selalu berubah.

Berdasarkan studi pendahuluan yang dilakukan oleh peneliti sendiri dengan mengamati Langsung siswa kelas X IPS tanggal 07 Agustus 2017 menunjukkan bahwa kemampuan berpikir kritis siswa sangat beragam pada siswa terutama dapat dilihat dari kurangnya partisipasi aktif siswa dalam pembelajaran, rendahnya respon siswa dalam menjawab pertanyaan guru maupun memberikan pertanyaan, serta rendahnya keberanian siswa untuk tampil mengungkapkan pikiran dan pendapat di depan guru maupun temantemannya. Menghadapi kenyataan ini, peneliti ingin mencobakan suatu metode pembelajaran yang diasumsikan dapat berpengaruh positif terhadap kemampuan berpikir kritis siswa yaitu metode pembelajaran bertimbal balik (reciprocal teaching). Dalam beberapa penelitian yang telah dilakukan, diperoleh kesimpulan bahwa metode pembelajaran bertimbal balik (reciprocal teaching) berpengaruh positif terhadap kemampuan berpikir kritis siswa (Wati, 2016; Setiawan, dkk, 2016; Sophia, 2017; Munandar, 2018).

Model pembelajaran Reciprocal Teaching merupakan model pembelajaran yang memberikan kesempatan kepada siswa untuk belajar mandiri, kreatif, dan lebih aktif. Reciprocal Teaching adalah suatu pendekatan pembelajaran yang menerapkan empat strategi pemahaman mandiri, yaitu menyimpulkan bahan ajar, menyusun pertanyaan dan menyelesaikannya, menjelaskan kembali pengetahuan yang telah diperolehnya, kemudian memprediksikan pertanyaan selanjutnya dari persoalan yang disodorkan kepada siswa. Manfaatnya adalah dapat meningkatkan antusias siswa dalam pembelajaran karena siswa dituntut untuk aktif berdiskusi dan menjelaskan hasil pekerjaannya dengan baik sehingga penguasaan konsep suatu pokok bahasan Sejarah dapat dicapai (Setya, 2009). Sedangkan 
Pengaruh Metode Bertimbal Balik.....Celine dkk

menurut Palincsar dan Sullivan Reciprocal teaching memiliki empat tahapan yang dilakukan oleh siswa meliputi: klarifikasi (clarifying), prediksi (predicting), membuat pertanyaan (questioning), dan merangkum (summarizing).

Pengajaran bertimbal-balik merupakan satu pendekatan terhadap pengajaran siswa akan strategi-strategi belajar. Dengan Pengajaran bertimbal- balik guru mengajarkan siswa keterampilan-keterampilan kognitif penting dengan menciptakan pengalaman belajar melalui pemodelan perilaku tertentu dan kemudian membantu siswa mengembangkan keterampilan tersebut atas usaha mereka sendiri dengan pemberian semangat, dukungan dan suatu sistem scaffolding. Scaffolding adalah bimbingan yang diberikan oleh orang yang lebih tahu kepada orang yang kurang atau belum tahu (misalnya guru kepada siswa atau siswa yang pandai dengan siswa lain yang kurang pandai). Pada scaffolding kemampuan aktual siswa, yaitu kemampuan yang mampu dicapai oleh siswa dengan belajar sendiri dapat berkembang lebih tinggi dan lebih baik sehingga dicapai kemampuan potensialnya. Dengan demikian scaffolding mampu membantu siswa mengembangkan kemampuan aktualnya menjadi kemampuan potensialnya (Suprapto dalam Ghozali dan Fuad, 2008).

Melalui pengajaran bertimbal-balik guru mengajarkan siswa keterampilanketerampilan kognitif penting dengan menciptakan pengalaman belajar melalui pemodelan perilaku tertentu dan kemudian membantu siswa mengembangkan keterampilan tersebut atas usaha mereka sendiri dengan pemberian semangat dan dukungan. Proses ini akan mampu meningkatkan kemampuan berpikir siswa ke arah yang lebih tinggi. Oleh karena itu, dalam penelitian ini, peneliti ingin mengkaji "Pengaruh Metode Bertimbal Balik (Reciprocal Teaching) terhadap Kemampuan Berpikir Kritis Siswa pada Mata Pelajaran Sejarah Kelas X IPS MA NW Kabar”.

\section{METODE PENELITIAN}

Dalam penelitian ini metode penelitian yang digunakan adalah metode eksperimen, dimana metode eksperimen menurut Sugiyono (2012: 107) metode eksperimen merupakan metode yang menjadi bagian dari metode kuantitatif yang mempunyai ciri khas tersendiri, yaitu dengan adanya kelompok kontrolnya. Desain 
Pengaruh Metode Bertimbal Balik.....Celine dkk

eksperimen yang digunakan adalah Nonequivalent Control Group Design yang merupakan bentuk metode penelitian eksperimen semu (quasi eksperiment). Desain penelitian dapat dilihat pada tabel berikut:

Tabel 1. Desain Penelitian

\begin{tabular}{|c|c|c|}
\hline KELOMPOK & PERLAKUAN & POST TES \\
\hline Eksperimen & $\mathrm{X}$ & $\mathrm{T} 1$ \\
\hline Kontrol & - & $\mathrm{T} 2$ \\
\hline
\end{tabular}

Sugiyono (2012: 116).

Tujuan penelitian ini adalah untuk menyelidiki ada tidaknya pengaruh tersebut dengan cara memberikan perlakuan tertentu pada kelas eksperimen dan menyediakan kelas kontrol. Pembelajaran pada kelas eksperimen memperoleh perlakuan dengan menggunakan metode bertimbal balik (reciprocal teaching) sedangkan pembelajaran pada kelas kontrol tidak memperoleh perlakuan menggunakan metode bertimbal balik (reciprocal teaching). Pada akhir pertemuan siswa diberi posttest, yaitu dengan memberikan angket kemampuan berpikir kritis yang dilakukan pada kedua kelas sampel dengan angket yang sama untuk mengetahui kemampuan berpikir kritis siswa pada mata pelajaran sejarah.

Populasi dalam penelitian ini adalah seluruh siswa kelas XI IPS SMAN 2 Aikmel yang terdiri dari 3 kelas. Selanjutnya Arikunto (2006: 134) mengemukakan apabila subyeknya kurang dari 100, lebih baik diambil semua sehingga penelitiannya merupakan penelitian populasi. Berdasarkan penjelasan tersebut, dalam penelitian ini tidak terdapat sampel penelitian, hal ini disebabkan karena populasi penelitiannya kurang dari 100 orang.

Ada dua variabel dalam penelitian ini, yakni variabel bebas dan variabel terikat. Variabel bebas $(\mathrm{X})$ yang memengaruhi variabel terikat. Variabel bebas dalam penelitian ini adalah "metode bertimbal balik (reciprocal teaching)". Variabel terikat (Y) yang menjadi akibat atau yang dipengaruhi oleh variabel bebas. Variabel terikat dalam penelitian ini adalah "Keterampilan Berpikir Kritis siswa Pada Mata Pelajaran Sejarah”. 
Pengaruh Metode Bertimbal Balik.....Celine dkk

Teknik pengumpulan data dalam penelitian ini menggunakan instrumen angket yang digunakan untuk mengukur kemampuan berpikir kritis siswa pada mata pelajaran sejarah. Dengan cara angket pada akhir pembelajaran (posttest), hasil posttest inilah yang merupakan data hasil kemampuan berpikir kritis siswa pada mata pelajaran sejarah. Angket ini diberikan kepada siswa secara individual, pemberiannya ditujukan untuk mengukur kemampuan berpikir kritis siswa pada mata pelajaran sejarah. Angket yang digunakan adalah memiliki pilihan yaitu Sangat Setuju (SS), Setuju (S), Ragu-Ragu (RR), Tidak setuju (TS), dan Sangat Tidak Setuju (STS) pilihan ganda yang terdiri dari 25 butir pernyataan. Angket yang diberikan pada setiap kelas untuk posttest adalah sama. Uji hipotesis yang digunakan dalam penelitian ini adalah uji statistic parametrik, yaitu Independent sample t-test dengan menggunakan program SPSS 22.0.

\section{HASIL PENELITIAN DAN PEMBAHASAN}

Hasil penelitian ini dianalisis dengan bantuan program SPSS. Berikut ini adalah hasil analisis dekskriptif hasil penelitian.

Tabel 2. Deskripsi Hasil Penelitian

\begin{tabular}{|l|l|l|r|}
\hline \multicolumn{2}{|l|}{} & $\begin{array}{c}\text { Menggunakan } \\
\text { Metode Reciprocal } \\
\text { Teaching }\end{array}$ & $\begin{array}{c}\text { Tanpa Metode } \\
\text { Reciprocal } \\
\text { Teaching }\end{array}$ \\
\hline $\mathrm{N}$ & Valid & 30 & 30 \\
\hline & Missing & 0 & 0 \\
\hline Mean & 93.50 & 77.90 \\
\hline Median & 94.00 & 77.50 \\
\hline Mod & $91 \mathrm{a}$ & $65 \mathrm{a}$ \\
\hline e & 7.803 & 10.911 \\
\hline Std. Deviation & 60.879 & 119.059 \\
\hline Variance & 29 & 40 \\
\hline Range & 81 & 57 \\
\hline Minimum & 110 & 97 \\
\hline Maximum & 2805 & 2337 \\
\hline Sum & & \\
\hline
\end{tabular}

Multiple modes exist. The smallest value is shown 
Pengaruh Metode Bertimbal Balik.....Celine dkk

Dari 30 siswa yang diberikan perlakuan menggunakan metode Metode Bertimbal Balik (Reciprocal Teaching) didapatkan bahwa skor maksimum perolehan adalah 110 dan skor mimimun adalah 81, rata- ratanya adalah 93,50, median : 94,00, modus : 91, varian : 60,88 , range: 29 , dan standar deviasinya adalah 7,803. Sedangkan untuk kelompok kontrol diperoleh skor maksimum perolehan adalah 97 dan skor mimimun adalah 57, rata-ratanya adalah 77,90, median : 77,50, modus : 65, varian : 119,05, range: 40, dan standar deviasinya adalah 10,9. Dilihat dari nilai rata-rata kedua kelompok, diperoleh bahwa data hasil belajar siswa tergolong kategori tinggi, sedangkan untuk data kelompok kontrol tergolong kategori sedang. Dari hasil pengkategorian di atas maka dapat disimpulkan bahwa pengaruh metode bertimbal balik (Reciprocal Teaching) terhadap terhadap kemampuan berpikir kritis siswa pada mata pelajaran Sejarah pada siswa kelas XI IPS SMAN 2 Aikmel tahun pembelajaran 2018/2019 lebih tinggi daripada kelompok kontrol. Berdasarkan hasil pengujian hipotesis, diperoleh nilai t-hitung sebesar 6,370 dan t-tabel sebesar 2,00. Karena t-hitung > t-tabel, maka dapat disimpulkan bahwa uji hipotesis nol ditolak dan hipotesis alternatif diterima, yang artinya ada pengaruh penggunaan metode bertimbal balik (reciprocal teaching) terhadap kemampuan berpikir kritis siswa kelas XI IPS SMAN 2 Aikmel tahun pembelajaran 2018/2019.

Reciprocal teaching memiliki empat tahapan yang dilakukan oleh siswa meliputi: klarifikasi (clarifying), prediksi (predicting), membuat pertanyaan (questioning), dan merangkum (summarizing). Pada tahap clarifying siswa diminta untuk membaca materi kemudian menjelaskan bagian-bagian yang belum dipahami dari apa yang sudah dibaca. Tahap ini meminta siswa untuk memahami informasi yang dibacanya kemudian melakukan klarifikasi terhadap informasi tersebut dengan menentukan mana yang sudah dipahami dan mana yang belum dipahami. Melalui tahap ini, siswa mampu melakukan evaluasi yang merupakan salah satu indicator dari berpikir kritis. Tahap predicting, siswa diminta untuk memberikan prediksi terhadap hubungan antara materi yang dipelajari dengan materi berikutnya. Tentunya hal ini, dapat dilakukan jika siswa sudah memahami materi yang dipelajari. Pada tahap questioning, siswa diminta untuk membuat soal atau pertanyaan sendiri yang berkaitan dengan materi yang sedang dipelajari. Soal yang telah dibuat 
Pengaruh Metode Bertimbal Balik.....Celine dkk

diberikan kepada teman lain untuk dijawab, jawaban yang telah diberikan kemudian diberikan lagi kepada siswa yang membuat soal untuk memeriksanya. Tahap ini dapat melatih kemampuan evaluasi siswa, yaitu kemampuan untuk menguji kebenaran. Pada tahap summarizing, siswa diminta untuk merangkum materi pelajaran yang telah dipelajari, tahap ini dapat melatih kemampuan inferensi siswa, yaitu kemampuan untuk membuat suatu kesimpulan dari apa yang telah dipelajari. Tahapan-tahapan tersebut menuntut siswa untuk berpikir pada tingkatan yang lebih tinggi, sehingga metode pembelajaran reciprocal teaching dapat meningkatkan kemampuan berpikir kritis siswa. Terbukti bahwa metode pembelajaran reciprocal teaching berpengaruh positif terhadap kemampuan berpikir kritis siswa. Hal ini sejalan dengan penelitian yang dilakukan oleh Wati (2016); Setiawan, dkk,( 2016); Sophia, (2017); Munandar, (2018).

Melalui pembelajaran reciprocal teaching, aktivitas belajar yang dilakukan siswa dalam pembelajaran reciprocal teaching menjadi lebih kondusif. Siswa menjadi lebih tertantang untuk mencari informasi dengan dibimbing oleh guru. Hal tersebut menjadikan siswa menjadi lebih aktif.

\section{DAFTAR PUSTAKA}

Alfian, M. 2011. Pendidikan Sejarah dan Permasalahan yang dihadapi. Jurnal Ilmiah Kependidikan, 3(2): 1-8.

Arikunto, S. 2010. Prosedur Penelitian Suatu Pendekatan Praktik. Jakarta: Rineka Cipta.

Ennis, R.H. 1996. Critical thingking. New Jersey: Prentice Hall

Jensen, E. 2011. Pembelajaran Berbasis Otak, Paradigma Pembelajaran Baru. Jakarta: PT Indeks.

Fahrurrozi. 2011. Penerapan pembelajaran berbasis masalah untuk meningkatkan kemampuan berpikir kritis dan komunikasi matematis siswa sekolah dasar. Jurnal Penelitian Pendidikan UPI, (2): 76-89.

Ghozali, I. dan Fuad. 2008. Structural Equation Modeling. Semarang: Universitas Diponegoro.

Gunawan, A.W. 2003. Genius Learning Strategy. Jakarta: Gramedia

Hermanto, R. 2016. Peningkatan Berpikir Kritis pada Mata Pelajaran Sejarah Melalui Pendekatan Pembelajaran Konstruktivistik. Jurnal Pendidikan Sejarah, (5)1, DOI: https://doi.org/10.21009/JPS.051.01

Kusumaningsih, D. 2011. Upaya Meningkatkan Kemampuan Berpikir Kritis Siswa Kelas X-C SMA N 11 Yogyakarta Melalui Pembelajaran Matematika dengan Pendekatan 
Pengaruh Metode Bertimbal Balik.....Celine dkk

CTL . (Online) Tersedia : http:/eprints.uny.ac.id/1633/1/SKRIPSI.PDF. (18 November 2018).

Munandar, A. 2018. Pengaruh Model Pembelajaran Reciprocal Teaching Terhadap Kemampuan Berpikir Kritis Matematis Pada Siswa MTs. Skripsi. Banda Aceh: Universitas Islam Negeri Ar-Raniry.

Santrock, J.W. 2011. Psikologi Pendidikan, Edisi Kedua. Jakarta: Kencana.

Setiawan, D.C., A. D. Corebima, A.D., Zubaidah, S. 2016. Pengaruh Strategi Pembelajaran Reciprocal Teaching terhadap Kemampuan Berpikir Kritis Biologi Siswa SMA Islam Al-Ma'rif Singosari Malang. Biodik, (2)1: 7-12. ISSN. 2460-2612

Shopia, A., Mulyaningrum, E. R. 2017. Pengaruh Model Pembelajaran Reciprocal Teaching Berbantu Media Pictorial Riddle Terhadap Kemampuan Berpikir Kritis Dan Hasil Belajar Kognitif Siswa. (online). Tersedia: http://researchgate.net/.../321256430. diakses pada 12 Agustur 2018.

Sugiyono. 2012. Metode Penelitian Kuantitatif Kualitatif dan $R \& D$. Bandung: Alfabeta.

Wati, L.E. 2016. Pengaruh Model Reciprocal Teaching Pada Pembelajaran Ipa Terhadap Aktivitas Dan Kemampuan Berpikir Kritis Siswa Smp. Skripsi. Semarang: Universitas Negeri Semarang.

Wijaya, C. 2010. Pendidikan Remidial. Bandung: Remaja Rosdakarya. 